\title{
Temporal processing ability in above average and average readers
}

\author{
AGNES AU \\ City University of Hong Kong, Hong Kong, China \\ and \\ BILL LOVEGROVE \\ Griffith University, Nathan, Queensland, Australia
}

\begin{abstract}
In the present study, we compared the rapid visual and auditory temporal processing ability of above average and average readers. One hundred five undergraduates participated in various visual and auditory temporal tasks. The above average readers exhibited lower auditory and visual temporal resolution thresholds than did the average readers, but only the differences in the auditory tasks were statistically significant, especially when nonverbal IQ was controlled for. Furthermore, both the correlation and stepwise multiple regression analyses revealed a relationship between the auditory measures and the wide range achievement test (WRAT) reading measure and a relationship between the auditory measures and a low spatial frequency visual measure and the WRAT spelling measure. Discriminant analysis showed that together both the visual and auditory measures correctly classified $75 \%$ of the subjects into above average and average reading groups, respectively. The results suggest that differences in temporal processing ability in relation to differences in reading proficiency are not confined to the comparison between poor and normal readers.
\end{abstract}

A number of studies have shown that many dyslexics and language-impaired subjects have difficulty in processing rapidly presented stimuli, and that a lack of phonological awareness is a typical characteristic of these language learning problems (Witton et al., 1998). In vision, the temporal deficit has been interpreted as reflecting a weakness in the visual magnocellular pathway or the transient visual system (Lovegrove, Martin, \& Slaghuis, 1986), a visual subsystem that is primarily involved in the processing of low spatial and high temporal frequency stimuli (Baro, Garzia, \& Lehmkuhle, 1996). In reading, the transient system is involved in saccades and is partially concerned with integrating visual information across successive fixations (Lovegrove, 1991). Dyslexics, however, seem to have intact visual parvocellular pathways or the sustained visual system (Lovegrove et al., 1986), a subsystem that is primarily involved in the processing of high spatial and low temporal frequency stimuli (Baro et al., 1996). In reading, the sustained subsystem is more concerned with extracting detail within single fixations (Livingstone \& Hubel, 1988).

Some evidence of visual temporal processing deficits comes partially from studies that have demonstrated a loss of contrast sensitivity in dyslexics, especially when low spatial and high temporal frequency stimuli have been used. For instance, Martin and Lovegrove (1987) found

Correspondence concerning this article should be addressed to A. Au, Flat A, 9/F, 101 Broadway, Mei Foo Sun Chuen, Kowloon, Hong Kong (e-mail: auagnes@ netvigator.com). that dyslexics (mean age: 13 years) displayed higher contrast thresholds to $2 \mathrm{c} / \mathrm{deg}$ counterphased sine wave gratings compared with normal controls. However, Cornelissen, Richardson, Mason, Fowler, and Stein (1995) and Gross-Glenn et al. (1995) failed to replicate these findings in reading-disabled subjects with mean ages of 10 and 39 years, respectively. This failure has been attributed to the use of photopic luminance levels in their studies, a condition in which the sustained visual system contributes to and functions normally in dyslexics. Nevertheless, Demb, Boynton, Best, and Heeger (1997) did not find any differences between dyslexic adults (mean age: 22 years) and controls with respect to the contrast sensitivity to moving low spatial frequency sine wave gratings, even though the mesopic luminance level was adopted. Note that their stimuli were "windowed" by smooth functions that avoided sharp edges and temporal transients that might have aided detection. Furthermore, recent research into reading-disabled adults (mean age: 35 years; Borsting et al., 1996) and children (ages 8 to 14 years) (Slaghuis \& Ryan, 1999) reveals that such deficits occur only in subjects who have impaired phonological processes.

Other evidence for visual temporal deficits experienced by dyslexics can be cited from studies of visible persistence or gap detection. Slaghuis and Lovegrove (1985) showed that reading-disabled children (mean age: 9 years) exhibited longer visible persistence to low spatial frequency sine wave gratings. Dyslexics (ages 18-37) also needed longer interstimulus intervals (ISIs) in order to determine whether the four sides of a square were pre- 
sented simultaneously or sequentially (Winters, Patterson, \& Shontz, 1989). Similarly, Chase and Jenner (1993) found that dyslexic adults (ages 17-22) required higher fusion thresholds to detect whether the fused image formed by the spatiotemporal presentation of individual stimuli was an overlapping composite image. On the contrary, Howell, Smith, and Stanley (1981) failed to replicate Lovegrove's findings with dyslexic boys (ages 10-14). In their experiment, the use of a cathode ray oscilloscope, which eliminates the transient artifacts during stimulus presentation, might explain this discrepancy (Slaghuis \& Lovegrove, 1986). Likewise, Hogben, Rodino, Clark, and Pratt (1995) failed to report any visible persistence differences between dyslexics (mean age: 9 years) and their chronological-age-matched controls when they used a matrix-integration technique. In that task, a $4 \times 4$ dot matrix with a missing dot was presented in two frames: eight dots in the first frame and seven dots in the second, with an intervening ISI. The subjects had to indicate where the dot was missing in the matrix. The close distance between the dots might have enhanced the involvement of the sustained visual system during the detail analysis required by the task.

Meanwhile, there is also evidence that the auditory temporal deficits experienced by the reading-disabled and language-impaired subjects are related to abnormalities found in the auditory magnocellular pathways in the medial geniculate nucleus (Galaburda \& Livingstone, 1993). To illustrate this, Kraus et al. (1996) showed that learning-disabled children (ages 6-15 years) had difficulty in discriminating rapid speech change, such as /da/ vs. /ga/ and /ba/vs. /wa/. Reading-disabled children (ages 7-9) also had larger fusion points for tone pairs between 250 and $400 \mathrm{~Hz}$ (McCroskey \& Kidder, 1980). In addition, dyslexic adults required longer click intervals than did controls to perceive trains of binaural clicks as separate (Hari \& Kiesila, 1996). Recent evidence suggests that auditory temporal processing ability is predictive of subsequent language skills development. Trehub and Henderson (1996) measured the gap detection thresholds of $500-\mathrm{Hz}$ tones in infants who were either 6 or 12 months of age. Infants with better temporal resolution were subsequently reported to have larger productive vocabulary and to generate more irregular word forms and longer and more complex sentences. Moreover, infants (6 months of age) from families with positive history of language impairment had significantly higher gap detection thresholds to 75 -msec tone sequences (100 and $300 \mathrm{~Hz}$ ), in comparison with the control infants (Benasich \& Tallal, 1996).

Lowe and Campbell (1965) found that languageimpaired children (ages $7-14$ years) took more time to report the order of two $15-\mathrm{msec}$ tones $(400 \mathrm{~Hz}$ and $2200 \mathrm{~Hz}$ ). Similar results were obtained with languageimpaired boys (ages 8-11) in Ludlow, Cudahy, Bassich, and Brown (1983). Reed (1989) reported that dyslexics (mean age: 9 years) were impaired in their judging the order of 75-msec tones and stop consonant syllables at short ISIs. The author argued for a perceptual deficit in the processing of brief auditory cues in dyslexia. Nonetheless, the dyslexics (ages 7.5-9) investigated by Tallal and Stark (1982) did not have concomitant language disorders and showed normal phonological decoding skills and normal temporal processing abilities. These findings parallel those of visual task studies, in that the temporal deficit appears only in subjects with phonological impairment. Nevertheless, Mody, Studdert-Kennedy, and Brady (1997) concluded that the inability of the reading-disabled subjects to discriminate rapidly presented syllables stemmed from a speech-specific failure rather than from auditory temporal processing capacity. In their experiment, reading-impaired children in the second grade were asked to report the order of synthetic syllables. These children had difficulty only with similar syllables such as $/ \mathrm{ba} /-/ \mathrm{da} /$ and not dissimilar syllables such as /ba/-/sa/ and /da/-/ Ja/. However, concerns over the authors' interpretation of the results have been raised by Denenberg (1999), particularly with respect to (1) the selection of reading-disabled children with a reading lag of less than 1 year, (2) the violation of statistical assumptions, and (3) conclusions that were based on the failure to obtain significant differences.

Furthermore, Galaburda and Livingstone (1993) have provided a general theoretical framework for the integration of the extensive data on both visual and auditory deficits in dyslexics. They argue that most sensory and motor systems are subdivided into fast and slow subdivisions analogous to the transient and sustained systems in vision. Dyslexics might perform more poorly than normal readers in resolving rapidly presented stimuli in more than one modality (Farmer \& Klein, 1995; Galaburda, Menard, \& Rosen, 1994; Miller \& Tallal, 1995; Stein, 1993). Only a few studies have examined the relationship among reading ability and both the visual and auditory temporal variables. Tallal, Stark, and Mellits (1985a) administered a battery of tests that incorporated auditory, visual, and cross-modal nonverbal and verbal stimuli to a group of language-impaired children (ages 5-8.5). Six variables, all of which were used to assess temporal perception and production ability, discriminated $98 \%$ of the subjects. Of particular importance was the involvement of syllable discrimination (/ba/vs. /da/) with 40-msec-duration formant transitions, as well as the cross-modal perception of tones and flashes in subject classification. Although Zhang and Tomblin (1998) noted critically that any large variable set that includes 160 variables can result in the selection of 6 variables that have high predictive accuracy between the two populations, the selection of variables that are all temporal in nature is the key to the research (Tallal, 1999). Recently, Witton et al. (1998) demonstrated that dyslexic adults (mean age: 30 years) were less sensitive to rates of auditory frequency modulation of 2 and $40 \mathrm{~Hz}$, as well as to dynamic 
visual-motion stimuli. Moreover, the visual and the auditory measures predicted nonsense-word reading well in both dyslexic and normal readers.

In spite of the temporal deficits found in dyslexics and language-impaired subjects, little research has addressed the relationshipbetween temporal processing and reading in normal readers. In fact, differences in sensory temporal processing ability in relation to reading ability might not be confined to the comparison between dyslexics and normal readers. McAnally and Stein (1996) and Witton et al. (1998) suggested that temporal processing ability might predict reading ability in normal and dyslexic readers. Accordingly, it is necessary to investigate the function of the temporal mechanisms in relation to reading ability in normal readers before one can proceed to a further understanding of the function of the same mechanism in dyslexics. Therefore, normal-reading university students rather than dyslexics were tested in this study.

The aim of this investigation, therefore, was to compare sensory temporal processing abilities in above average and average readers. On the basis of the studies stated above, it was hypothesized that above average readers would perform better than average readers in a range of visual and auditory temporal processing tasks. Because of equipment constraints, we administered flicker contrast sensitivity, visible persistence, auditory gap detection, and temporal order judgment tasks in the study. Moreover, because the transient visual systems in readingdisabled and language-impaired subjects are impaired, on the basis of spatiotemporal properties of the transient and sustained visual systems, the above average readers were expected to perform much better on the low spatial frequency or high temporal frequency visual measures than on the high spatial frequency or low temporal frequency visual measures.

\section{METHOD}

\section{Subjects}

The subjects were 105 undergraduate students with normal or corrected-to-normal vision, normal hearing, and no history of epilepsy, migraine headache, or ear infections. All were Englishspeaking psychology students who were offered bonus points for their participation; all had a nonverbal IQ of 85 or above, as measured by the Advanced Raven's Progressive Matrices test.

The subjects who scored at or above the 75th percentile in both the Wide Range Achievement Test (WRAT) reading and spelling measure were considered above average readers, whereas those who scored below the 75th percentile in both the WRAT reading and spelling measures were considered average readers. Using these criteria, 31 above average readers and 46 average readers were identified. The subjects $(n=28)$ who scored at or above the 75 th percentile in one of the WRAT measures and scored below the 75th percentile in the other were not included in the analysis.

\section{Tests}

The study consisted of four experimental sessions. The first session consisted of the Advanced Raven's Progressive Matrices (IQ) test. The second session consisted of the WRAT. The third session consisted of visible persistence, auditory gap detection, and auditory temporal order judgment (TOJ) tasks. The last session consisted of the flicker contrast sensitivity task. Test conditions were counterbalanced within each session.

\section{Measure 1A:}

\section{Flicker Contrast Sensitivity (FSEN)}

Apparatus and Stimuli. Following darkness adaptation under the binocular viewing condition, the subjects were seated at a distance of $57 \mathrm{~cm}$ from a Tektronix $608 \mathrm{X}-\mathrm{Y}$ display. Whole fields flickering sinusoidally at temporal frequencies of 2 and $12 \mathrm{~Hz}$, respectively, were generated on the $\mathrm{X}-\mathrm{Y}$ display with a $\mathrm{P} 31$ phosphor by an Innisfree Picasso CRT image generator. The stimulus size was $5^{\circ}$ of visual angle. Contrast thresholds were measured using Wetherill and Levitt's (1965) up-down-threshold-reversal method with a two-alternative forced-choice paradigm (converging on $79 \%$ of correct trials). The stimulus duration was $1 \mathrm{sec}$. Time averaged luminance was held constant at $10.3 \mathrm{~cd} / \mathrm{m}^{2}$ across all temporal frequency and contrast changes. The mesopic luminance level presumes that the subject's contrast threshold is primarily manipulated by the transient visual system; Cornelissen et al. (1995) showed that the flicker contrast sensitivity of dyslexics did not differ from that of controls in photopic luminance levels, conditions in which the sustained visual system can contribute. The room illumination was less than $1 \mathrm{~cd} / \mathrm{m}^{2}$. A white rectangular board, $83 \times 70 \mathrm{~cm}$, surrounded the $\mathrm{X}-\mathrm{Y}$ display and was illuminated by adjustable lights in such a way that no extra light fell on the $\mathrm{X}-\mathrm{Y}$ display screen. The average luminance of the surround was equal to the space-average luminance of the screen of the $\mathrm{X}-\mathrm{Y}$ display.

Procedure. The subjects were instructed to fixate on the circular field. On each trial, a high tone beep lasting $2 \mathrm{msec}$ was presented first, followed by either a flickering or a blank field. Then a low tone beep was presented, followed by the remaining stimulus, which had not been presented after the first beep. A third beep, which was a high tone beep, was presented afterward to indicate the end of the trial. The subjects were to report whether the flickering field followed the first or second beep. Feedback was given to the subjects and their contrast thresholds were recorded. The subjects were given practice before the experimental trials with temporal frequencies of 2 and $12 \mathrm{~Hz}$. The order of presentation for both conditions was counterbalanced.

\section{Measure 1B:}

\section{Visible Persistence (BLAN)}

Apparatus and Stimuli. The subjects were seated at a distance of $129 \mathrm{~cm}$ from a tachistoscope display. Viewing was binocular throughout. Vertical square wave gratings of spatial frequencies of 2 and $12 \mathrm{c} / \mathrm{deg}$, which completely filled a $6.74 \times 4.53^{\circ}$ target field, were presented via a tachistoscope. On each trial, the gratings were presented for $200 \mathrm{msec}$ and alternated with a variable blank ISI for 10 cycles. The duration of the blank ISI was the dependent variable. The luminance was held constant at $4.8 \mathrm{~cd} / \mathrm{m}^{2}$ across all spatial frequency changes.

Procedure. Each trial consisted of a grating-blank-grating cycle that repeated 10 times. The subjects were to report the presence or absence of a clear blank interval between the gratings. The ISIs were recorded using a random staircase method. The subjects were given practice before the experimental trials and were to respond to spatial frequencies of 2 and $12 \mathrm{c} / \mathrm{deg}$. The order of presentation for both conditions was counterbalanced.

\section{Measure 2A:}

Auditory Gap Detection of Noise (AGAP)

Apparatus and Stimuli. The stimuli consisted of continuous white noise or paired bursts of noise separated by a gap of variable duration (ISI). The total duration of the stimuli was either 15 or $100 \mathrm{msec}$.

The stimuli were generated by the National Semiconduct or MM5837 digital noise source and a Realistic STA-76 IC/FET AM/FM 
stereo receiver and were presented to the subjects through Sony MDR CD250 headphones at $60 \mathrm{~dB}$. The apparatus was placed in an adjacent room to ensure that noise from the computer fan did not disturb the subjects. Noise detection was performed to ensure that the subjects could hear the noise properly.

Procedure. On each trial, the subjects heard either two small bursts of noise followed by a single burst of noise, or vice versa. Their task was to indicate in which interval the paired bursts of noise occurred. The subjects were given practice before the experimental trials and were to respond to noise bursts of 15 and $100 \mathrm{msec}$. The order of presentation for both conditions was counterbalanced. The mean ISI in which the paired bursts of noise were to be distinguished was recorded using Wetherill and Levitt's (1965) procedure.

\section{Measure 2B:}

\section{Auditory Temporal Order Judgment (ATOJ)}

Apparatus and Stimuli. The stimulus was a pair of sine wave tones - a high tone $(2200 \mathrm{~Hz})$ and a low tone $(400 \mathrm{~Hz})$. The tones had a ramped rise/fall time of $5 \mathrm{msec}$. The intensity of the tones was $60 \mathrm{~dB}$. The duration of the second tone was 15,75 , or $200 \mathrm{msec}$, depending on condition. The duration of the first was equal to the sum of the duration of the second plus the stimulus onset asynchrony (SOA).

The stimuli were generated by two Novatech DDS3 digital synthesizer boards in the dual-tone generator. In order to ramp the tones, the tones were amplitude modulated by a voltage source from a digital-to-analog board connected to the computer. The experimental setup was similar to that used in the auditory gap detection task. Tone detection was performed to ensure that the subjects had no hearing loss at the frequencies used in this study.

Procedure. On each trial, either the high or the low tone was presented first, with the onset of the second occurring at varying SOAs. The offset of both tones occurred simultaneously. The subjects' task was to determine which tone was presented first. The subjects were given practice before the experimental trials and were to respond to stimulus durations of 15,75 , and $200 \mathrm{msec}$. The order of presentation for the three conditions was counterbalanced. The mean SOA to distinguish the tones was recorded using Wetherill and Levitt's (1965) procedure.

\section{Results}

A $\log$ transformation was performed on the data to achieve normal distribution and homogeneous variance because the distributions of AGAP15 (auditory gap detection at the 15-msec condition) and the ATOJ (auditory temporal order judgment) measures were positively skewed, whereas the distributions of BLAN12 (visible persistence at $12 \mathrm{c} / \mathrm{deg}$ ), AGAP15, ATOJ15 (auditory temporal order judgment at $15 \mathrm{msec}$ condition), and ATOJ75 (auditory temporal order judgment at $75 \mathrm{msec}$ condition) were too peaked. All statistical analyses were based on the log-transformed data.

The means and standard deviations of the original and the log-transformed data of the above average and average readers are shown in Table 1.

Since the above average readers had higher nonverbal IQs than the average readers did $[t(75)=2.19, p<.05]$, the temporal measures were compared, using two statistical methods: (1) a multivariate analysis of variance (MANOVA), which compared the two groups without taking IQ into account; and (2) a multivariate analysis of covariance (MANCOVA), which took IQ as a covariate. The $\alpha$ level chosen was .05.




The MANOVA showed an overall group effect on the combined temporal processing measures [Wilks's $\lambda=$ $0.67 ; F(9,67)=3.71, p=.0008]$. Above average readers performed significantly better in AGAP100 (auditory gap detection at $100 \mathrm{msec}$ condition $[F(1,75)=9.4, p=$ $.003]$, ATOJ $15[F(1,75)=13.31, p=.0005]$, ATOJ75 $[F(1,75)=6.34, p=.014]$, and ATOJ200 (auditory temporal order judgment at $200 \mathrm{msec}$ condition) $[F(1,75)=$ $16.07, p=.0001]$ and performed marginally better in the low spatial frequency measure BLAN2 (visible persistence at $2 \mathrm{c} / \mathrm{deg})[F(1,75)=3.85, p=.054]$. The two groups did not differ in FSEN2 (flicker contrast sensitivity at $2 \mathrm{~Hz})[F(1,75)=0.12, p>.05]$, FSEN12 (flicker contrast sensitivity at $12 \mathrm{~Hz})[F(1,75)=0.74, p>.05]$, BLAN12 $[F(1,75)=0.3, p>.05]$, or AGAP15 $[F(1,75)=$ $1.79, p>.05]$.

However, once IQ was controlled for by the MANCOVA, the difference on BLAN2 diminished $[F(1,74)=3.04$, $p>.05$ ] even though the overall group differences on the combined temporal processing measures remained significant [Wilks's $\lambda=0.64 ; F(9,66)=4.04, p=.0004$ ] Above-average readers performed significantly better in AGAP100 $[F(1,74)=10.45, p=.0018]$, ATOJ 15 $[F(1,74)=13.08, p=.0005]$, ATOJ75 $[F(1,74)=5.02$, $p=.0281]$, and ATOJ $200[F(1,74)=15.56, p=.0002]$ only (see Table 1).

Pearson correlation coefficients were computed among the temporal processing measures, IQ, and the WRAT reading and spelling scores. As is shown in Table 2, AGAP100, the ATOJ measures, and IQ significantly correlated with WRAT reading, whereas BLAN2 (a low spatial frequency measure), the AGAP, and ATOJ measures significantly correlated with WRAT spelling.

Stepwise multiple regression analyses were performed in order to further investigate the relationship among the temporal processing measures, IQ, and the reading measures. The WRAT reading and spelling scores were entered as dependent variables individually, whereas the visual, auditory, and IQ measures were entered as independent variables. For WRAT reading, ATOJ200 entered into the regression equation first and accounted for $15.3 \%$ of the variance $[F(1,75)=13.59, p<.05]$. AGAP100 entered second, accounting for an additional $7 \%$ of the explained

Table 2

Pearson Correlation Coefficients for the Temporal, IQ, and Reading Measures $(N=77)$

\begin{tabular}{ccc}
\hline Temporal/IQ Measures & WRAT Reading & WRAT Spelling \\
\hline FSEN2 & -.166 & -.106 \\
FSEN12 & -.168 & -.117 \\
BLAN2 & -.163 & $-.318^{* *}$ \\
BLAN12 & -.098 & -.126 \\
AGAP15 & -.184 & $-.257^{*}$ \\
AGAP100 & $-.323^{* *}$ & $-.35^{* *}$ \\
ATOJ15 & $-.37^{* *}$ & $-.385^{* *}$ \\
ATOJ75 & $-.292^{*}$ & $-.307^{* *}$ \\
ATOJ200 & $-.392^{* *}$ & $-.403^{* *}$ \\
IQ & $.227^{*}$ & .209 \\
\hline
\end{tabular}

$* p<.05$, two tailed. $* * p<.01$, two tailed. variance $[F(2,74)=10.63, p<.05]$. IQ entered third, accounting for an additional $4.5 \%$ of the variance $[F(3,73)=$ $8.91, p<.05]$. No other variable added a significant amount of variance in the analysis. For WRAT spelling, ATOJ200 entered into the regression equation first and accounted for $16.2 \%$ of the variance $[F(1,75)=14.51$, $p<.05]$. AGAP100 entered second, accounting for an additional $8.4 \%$ of the explained variance $[F(2,74)=$ $12.07, p<.05]$. BLAN2 entered third, accounting for an additional $4.7 \%$ of the explained variance $[F(3,73)=$ $10.09, p<.05]$. No other variable added a significant amount of variance in the analysis.

A discriminant function analysis using both the visual and auditory measures as discriminants for the reading groups was performed on the data. Twenty-three out of $31(74.19 \%)$ of the above-average readers were categorized into the above-average reading group, and 35 out of $46(76.09 \%)$ of the average readers were categorized into the average reading group. The percentage of correctly classified grouped cases was $75.32 \%$, and the model was significant [Wilks's $\lambda=0.67 ; \chi^{2}(9)=28.48, p=.0008$ ]. The results indicate that the function was largely a measure of the transient visual system and auditory temporal processing and was effective in discriminating aboveaverage and average readers.

In sum, although above average readers displayed better visual and auditory temporal resolution than did the average readers, the visual difference failed to reach significance when IQ was taken into account. Nevertheless, the correlation and multiple regression analyses illustrated the predictive power of the transient visual measure (as implicated by the low spatial frequency measure) in spelling, even though the auditory measures played a more dominant role in predicting both reading and spelling. Further, the transient visual measure and the auditory temporal processing measures, together, significantly discriminated the reading groups.

\section{DISCUSSION}

The most significant finding of the present study was that above-average readers exhibited better temporal resolution than did the average readers. The results extend previous research regarding the temporal deficits among poor readers by demonstrating that the relationship between temporal processing ability and an individual's reading level is not confined to the comparison between normal and reading-disabled/language-impaired subjects. The data in this study address the issue of whether dyslexia is a distinct disorder or whether it represents the lower end of the normal distribution of reading skills. The present finding that better temporal processing abilities are related to better reading abilities within the normal range is compatible with what has previously been reported primarily for impaired populations. The results support the hypothesis that dyslexia and other language-based learning disabilities lie along the normal continuum of language skills, albeit at the lower end of the normal distribution, rather 
than represent a distinct disorder (as would be evidenced by a hump at the lower end of the normal distribution as found in Rutter \& Yule [1975]). Thus, this study provides further evidence that dyslexia and other language disabilities represent the lower end of a normal continuum (see Shaywitz, Escobar, Shaywitz, Fletcher, \& Makuch, 1992).

Above-average readers performed better than average readers in a measure of auditory gap detection (100-msec condition) and in the auditory temporal order judgment tasks. Bryden (1972), Farmer and Klein (1993), Gould and Glencross (1990), Reed (1989), and Tallal and Piercy (1973) found that dyslexics were more likely to be impaired in the auditory than in the visual tasks. Our results also show a similar difference between average and aboveaverage readers. Meanwhile, more noticeable differences are obtained for the auditory temporal order judgment measures than for the gap detection measures. The data are consistent with Lowe and Campbell (1965) and Ludlow et al. (1983), who found that language-impaired children experienced more difficulty with TOJ than with gap detection tasks. Results of the multiple regression analyses further support the findings that auditory temporal processing measures account for more of the variance in reading performance (which accounted for $72 \%$ of the variance in Tallal, Stark, \& Mellits [1985b]) than do the visual temporal processing measures (which accounted for 5\%-15\% of the variance in Eden, Stein, \& F. B. Wood [1993] and in Eden, Stein, H. M. Wood, \& F. B. Wood [1995] and Eden, Stein, M. H. Wood, \& F. B. Wood [1995]).

The lack of significant visual differences, particularly when IQ was taken into account, might be attributed to, first, the comparison within normal and not between normal and reading-disabled subjects. In the former type of comparison, the differences may be too subtle. As a matter of fact, a recent demonstration by Conlon, Zapart, Chekaluk, Lovegrove, and Mellor (1999) showed that adult poor spellers who had difficulty in reading nonsense words performed worse in a temporal dot counting task and in a random coherent motion task than did the normal controls. Thus, it is conceivable that a larger reading or spelling discrepancy between the reading groups might make the visual differences more apparent. Second, significant visual differences may be less evident in highly skilled adult readers than in children. Third, the relationship between intelligence, particularly performance IQ, and visual temporal processing has been documented in some visual inspection time studies (Bowling \& Mackenzie, 1996; Deary, 1993; Stough et al., 1996; but see also Mackenzie et al., 1989; Whyte, Curry, \& Hale, 1985). Accordingly, visual temporal processing and intelligence may undermine each other and thus the statistical control of IQ might have masked the visual differences in the present study.

Despite the superiority of the auditory measures over the visual measures in differentiating above-average from average readers, the data suggest the relevance of the transient visual system in spelling. On the basis of the association between poor spelling and phonological pro- cessing deficits (Bruck \& Waters, 1988, 1990; Snowling, Stackhouse, \& Rack, 1986), our findings confirm the relationship between phonological awareness and visual temporal processing found in Lovegrove, Pepper, Martin, Mackenzie, and McNicol (1989) and in Witton et al. (1998), and the relationship between phonological awareness and auditory temporal processing found in Tallal et al. (1985b). Likewise, the results of our discriminant analysis further corroborate Tallal et al. (1985a) in that temporal processing variables (auditory, visual, crossmodal, and tactile) can correctly classify subjects as normal or language impaired.

To conclude, our study shows that above-average readers, as compared with average readers, display better auditory temporal resolution. Limited evidence of the involvement of the transient visual system in spelling is provided. Nevertheless, both the auditory and the transient visual measures remain useful discriminants for the reading groups. Our study further supports the notion that dyslexia and other language disabilities represent the lower end of a normal continuum of language skills.

\section{REFERENCES}

Baro, J. A., Garzia, R. P., \& Lehmkuhle, S. (1996). Visual evoked potentials in reading disability. In R. P. Garzia (Ed.), Vision and reading (pp. 193-207). St. Louis: Mosby.

Benasich, A. A., \& Tallal, P. (1996). Auditory temporal processing thresholds, habituation, and recognition memory over the 1st year. Infant Behavior \& Development, 19, 339-357.

Borsting, E., Ridder, W. H., Dudeck, K., Kelley, C., Matsui, L., \& Motoyama, J. (1996). The presence of a magnocellular defect depends on the type of dyslexia. Vision Research, 36, 1047-1053.

Bowling, A. C., \& Mackenzie, B. D. (1996). The relationship between speed of information processing and cognitive ability. Personality \& Individual Differences, 20, 775-800.

BRUCK, M., \& WATERS, G. S. (1988). An analysis of the spelling errors of children who differ in their reading and spelling skills. Applied Psycholinguistics, 9, 77-92.

BRUCK, M., \& Waters, G. S. (1990). An analysis of the component spelling and reading skills of good readers-good spellers, good readerspoor spellers, and poor readers-poor spellers. In T. H. Carr \& B. A. Levy (Eds.), Reading and its development: Component skills approaches (pp. 161-206). San Diego: Academic Press.

BRYDEN, M. P. (1972). Auditory-visual and sequential-spatial matching in relation to reading ability. Child Development, $\mathbf{4 3}, 824-832$.

Chase, C., \& Jenner, A. R. (1993). Magnocellular visual deficits affect temporal processing of dyslexics. In P. Tallal et al. (Eds.), Temporal information processing in the nervous system: Special reference to dyslexia and dysphasia (Annals of the New York Academy of Sciences, Vol. 682, pp. 326-329). New York: New York Academy of Sciences.

Conlon, E., Zapart, S., Chekaluk, E., Lovegrove, B., \& Mellor, S. (1999). The magnocellular deficit in sub-types of poor adult spellers. Paper presented at the 26th Experimental Psychology Conference, Macquarie University, Sydney, Australia.

Cornelissen, P., Richardson, A., Mason, A., Fowler, S., \& Stein, J. (1995). Contrast sensitivity and coherent motion detection measured at photopicluminance levels in dyslexics and controls. Vision Research, 35, 1483-1495.

DEARY, I. J. (1993). Inspection time and WAIS-R IQ subtypes: A confirmatory factor analysis study. Intelligence, 17, 223-236.

Demb, J. B., Boynton, G. M., Best, M., \& Heeger, D. J. (1997). Psychophysical evidence for a magnocellular pathway deficit in dyslexia. Vision Research, 38, 1555-1559.

Denenberg, V. H. (1999). A critique of Mody, Studdert-Kennedy, and 
Brady's "Speech perception deficits in poor readers: Auditory processing or phonological coding?" Journal of Learning Disabilities, 32, 379-383.

Eden, G. F., Stein, J. F., \& Wood, F. B. (1993). Visuospatial ability and language processing in reading disabled and normal children. In S. F. Wright \& R. Groner (Eds.), Facets of dyslexia and its remediation: Studies in visual information processing. Vol. 3 (pp. 321-335). Amsterdam: Elsevier, North-Holland.

Eden, G. F., Stein, J. F., Wood, H. M., \& Wood, F. B. (1995). Temporal and spatial processing in reading disabled and normal children. Cortex, 31, 451-468.

Eden, G. F., Stein, J. F., Wood, M. H., \& Wood, F. B. (1995). Verbal and visual problems in reading disability. Journal of Learning Disabilities, 28, 272-290.

FARMer, M. E., \& Klein, R. (1993). Auditory and visual temporal processing in dyslexic and normal readers. In P. Tallal et al. (Eds.), Temporal information processing in the nervous system: Special reference to dyslexia and dysphasia (Annals of the New York Academy of Sciences, Vol. 682, pp. 339-341). New York: New York Academy of Sciences.

FARMer, M. E., \& KLEIN, R. M. (1995). The evidence for a temporal processing deficit linked to dyslexia: A review. Psychonomic Bulletin \& Review, 2, 460-493.

Galaburda, A. M., \& Livingstone, M. (1993). Evidence for a magnocellular defect in developmental dyslexia. In P. Tallal et al. (Eds.), Temporal information processing in the nervous system: Special reference to dyslexia and dysphasia (Annals of the New York Academy of Sciences, Vol. 682, pp. 70-82). New York: New York Academy of Sciences.

Galaburda, A. M., Menard, M. T., \& Rosen, G. D. (1994). Evidence for aberrant auditory anatomy in developmental dyslexia. Proceedings of the National Academy of Sciences, 91, 8010-8013.

Gould, J. H., \& Glencross, D. J. (1990). Do children with a specific reading disability have a general serial-ordering deficit? Neuropsychologia, 28, 271-278.

Gross-Glenn, K., Skottun, B. C., Glenn, W., Kushch, A. Lingua, R. Dunbar, M., Jallad, B., Lubs, H. A., Levin, B., Rabin, M., Parke, L. A., \& DuAra, R. (1995). Contrast sensitivity in dyslexia. Visual Neuroscience, 12, 153-163.

HARI, R, \& Kiesila, P. (1996). Deficit of temporal auditory processing in dyslexic adults. Neuroscience Letters, 205, 138-140.

Hogben, J. H., Rodino, I. S., Clark, C. D., \& Pratt, C. (1995). A comparison of temporal integration in children with a specific reading disability and normal readers. Vision Research, 35, 2067-2074.

Howell, E. R., Smith, G. A., \& Stanley, G. (1981). Reading disability and visual spatial frequency specific effects. Australian Journal of Psychology, 33, 97-102.

Kraus, N., McGee, T. J., Carrell, T. D., Zecker, S. G., Nicol, T. G., \& KocH,D. B. (1996). Auditory neurophysiologicresponses and discrimination deficits in children with learning problems. Science, 273, 971-973.

Livingstone, M., \& Hubel, D. (1988). Segregation of form, color, movement and depth: Anatomy, physiology and perception. Science, 240, 740-749.

LOVEGrove, W. (1991). Is the question of the role of visual deficits as a cause of reading disabilities a closed one? Comments on Hulme. Cognitive Neuropsychology, 8, 435-441.

Lovegrove, W., Martin, F., \& Slaghuis, W. (1986). A theoretical and experimental case for a visual deficit in specific reading disability. $\mathrm{Cog}$ nitive Neuropsychology, 3, 225-267.

Lovegrove, W., Pepper, K., Martin, F., Mackenzie, B., \& McNicol, D. (1989). Phonological recoding, memory processing and visual deficits in specific reading disability. In D. Vickers \& P. L. Smith (Eds.), Human information processing: Measures, mechanisms and models (pp. 65-79). Amsterdam: Elsevier, North-Holland.

Lowe, A. D., \& CAMpBell, R. A. (1965). Temporal discrimination in aphasoid and normal children. Journal of Speech \& Hearing Research, 8, 313-314.

Ludlow, C. L., Cudahy, E. A., Bassich, C., \& Brown, G. L. (1983).
Auditory processing skills of hyperactive, language impaired and reading disabled boys. In E. Z. Lasky \& J. Katz (Eds.), Central auditory processing disorders (pp. 163-184). Baltimore: University Park Press.

Mackenzie, B., Bingham, E., Cumming, S., Doyle, P., Turner, C., Molloy, E., Martin, F., Alexander, J., \& Lovegrove, W. (1989). Inspection time is related to intelligence in some subjects but not in all. In D. Vickers \& P. L. Smith (Eds.), Human information processing: Measures, mechanisms and models (pp. 487-495). Amsterdam: Elsevier, North-Holland.

Martin, F., \& Lovegrove, W. (1987). Flicker contrast sensitivity in normal and specifically disabled readers. Perception, 16, 215-221.

McAnally, K. I., \& Stein, J. F. (1996). Auditory temporal coding in dyslexia. Proceedings of the Royal Society of London: Series B, 263, 961-965.

McCroskey, R. L., \& Kidder, H. C. (1980). Auditory fusion among learning disabled, reading disabled, and normal children. Journal of Learning Disabilities, 13, 69-76.

Miller, S. L., \& TAllal, P. (1995). A behavioral neuroscience approach to developmental language disorders: Evidence for a rapid temporal processing deficit. In D. Cicchetti \& D. J. Cohen (Eds.), Developmental psychopathology: Vol. 2. Risk, disorder and adaptation (pp. 274-298). New York: Wiley.

Mody, M., Studdert-Kennedy, M., \& Brady, S. (1997). Speech perception deficits in poor readers: Auditory processing or phonological coding? Journal of Experimental Child Psychology, 64, 199-231.

REED, M. A. (1989). Speech perception and the discrimination of brief auditory cues in reading disabled children. Journal of Experimental Child Psychology, 48, 270-292.

RUtTer, M., \& Yule, W. (1975). The concepts of specific reading retardation. Journal of Child Psychology \& Psychiatry, 16, 181-197.

Shay witz, S. E., Escobar, M. D., Shay witz, B. A., Fletcher, J. M., \& MAKUCH, R. (1992). Evidence that dyslexia may represent the lower tail of a normal distribution of reading ability. New England Journal of Medicine, 326, 145-150.

Slaghuis, W. L., \& Lovegrove, W. J. (1985). Spatial-frequency, dependent visible persistence and specific reading disability. Brain Cognition, 4, 219-240.

Slaghuis, W. L., \& Lovegrove, W. J. (1986). The effect of physical flicker on visible persistence in normal and specifically disabled readers. Australian Journal of Psychology, 38, 1-11.

Slaghuis, W. L., \& RYan, J. F. (1999). Spatio-temporal contrast sensitivity, coherent motion, and visible persistence in developmental dyslexia. Vision Research, 39, 651-668.

SNOWling, M. J., StACKhouse, J., \& Rack, J. (1986). Phonological dyslexia and dysgraphia: Developmental aspects. Cognitive Neuropsychology, 3, 309-339.

SteIN, J. (1993). Dyslexia-impaired temporal information processing? In P. Tallal et al. (Eds.), Temporal information processing in the nervous system: Special reference to dyslexia and dysphasia (Annals of the New York Academy of Sciences, Vol. 682, pp. 83-86). New York: New York Academy of Sciences.

Stough, C., Brebner, J., Nettlebeck, T., Cooper, C. J., Bates, T., \& Mangan, G. L. (1996). The relationship between intelligence, personality and inspection time. British Journal of Psychology, 87, 255-268.

TALlal, P. (1999). Children with language impairment can be accurately identified using temporal processing measures: A response to Zhang and Tomblin, Brain \& Language, 65, 395-403 (1998). Brain \& Language, 69, 222-229.

TAllal, P., \& Piercy, M. (1973). Developmental aphasia: Impaired rate of non-verbal processing as a function of sensory modality. Neuropsychologia, 11, 389-398.

TAllal, P., \& STARK, R. E. (1982). Perceptual/motor profiles of reading impaired children with or without concomitant oral language deficits. Annals of Dyslexia, 32, 163-176.

Tallal, P., Stark, R. E., \& Mellits, D. (1985a). Identification of language-impaired children on the basis of rapid perception and production skills. Brain \& Language, 25, 314-322.

Tallal, P., Stark, R. E. \& Mellits, D. (1985b). The relationship be- 
tween auditory temporal analysis and receptive language development: Evidence from studies of developmental language disorder. Neuropsychologia, 23, 527-534.

Trehub, S. E., \& Henderson, J. L. (1996). Temporal resolution in infancy and subsequent language development. Journal of Speech \& Hearing Research, 39, 1315-1320.

Wetherill, G. B., \& Levitt, H. (1965). Sequential estimation of points on a psychometric function. British Journal of Mathematical \& Statistical Psychology, 18, 1-10.

Whyte, J., Curry, C., \& Hale, D. (1985). Inspection time and intelligence in dyslexic children. Journal of Child Psychology \& Psychiatry \& Allied Disciplines, 26, 423-428.

Winters, R. L., Patterson, R., \& Shontz, W. (1989). Visual persistence and adult dyslexia. Journal of Learning Disabilities, 22, 641-645.
Witton, C., Talcott, J. B., Hansen, P. C., Richardson, A. J., Griffiths, T. D., Rees, A., Stein, J. F., \& Green, G. G. R. (1998). Sensitivity to dynamic auditory and visual stimuli predicts nonword reading ability in both dyslexic and normal readers. Current Biology, 8 , 791-797.

Zhang, X., \& Tomblin, J. B. (1998). Can children with language impairment be accurately identified using temporal processing measures? Brain \& Language, 65, 395-403.

(Manuscript received June 30, 1999; revision accepted for publication January 28,2000 .) 